\title{
Does long-term care coverage shape the impact of informal care-giving on quality of life? A difference-in-difference approach
}

\author{
Thijs van den Broek ${ }^{1 \star}$ and Emily Grundy ${ }^{2}$ \\ ${ }^{1}$ ALPHA Research Unit, Department of Social Policy, London School of Economics and Political Science, \\ London, UK and ${ }^{2}$ Institute for Social and Economic Research, University of Essex, Colchester, UK \\ ${ }^{\star}$ Corresponding author. Email: m.p.van-den-broek@lse.ac.uk
}

(Accepted 22 November 2018; first published online 27 December 2018)

\begin{abstract}
The impact that providing care to ageing parents has on adult children's lives may depend on the long-term care (LTC) context. A common approach to test this is to compare whether the impact of care-giving varies between countries with different LTC coverage. However, this approach leaves considerable room for omitted variable bias. We use individual fixed-effects analyses to reduce bias in the estimates of the effects of informal caregiving on quality of life, and combine this with a difference-in-difference approach to reduce bias in the estimated moderating impact of LTC coverage on these effects. We draw on longitudinal data for Sweden and Denmark from the Survey of Health, Ageing and Retirement in Europe (SHARE) collected between 2004 and 2015. Both countries traditionally had generous LTC coverage, but cutbacks were implemented at the end of the 20th century in Sweden and more recently in Denmark. We use this country difference in the timing of the cutbacks to shed light on effects of LTC coverage on the impact caregiving has on quality of life. Our analyses show that care-giving was more detrimental for quality of life in Sweden than in Denmark, and this difference weakened significantly when LTC coverage was reduced in Denmark, but not in Sweden. This suggests that LTC coverage shapes the impact of care-giving on quality of life.
\end{abstract}

Keywords: intergenerational support; informal care; long-term care; re-familialisation; wellbeing; causal inference

\section{Introduction}

When parents develop health limitations adult children often take on support tasks in response (Silverstein et al., 2006; Blomgren et al., 2012). The extent to which adult children feel compelled to do this and the impact that care-giving has on their lives may depend on the long-term care (LTC) context. In many European countries, and in particular in those that were traditionally characterised by generous state provision of LTC services, responsibilities for the care of older persons 
with health limitations have increasingly been shifted from the state to informal networks, most notably the family (Pavolini and Ranci, 2008; Ranci and Pavolini, 2015). Given that providing informal care is associated with a wide range of economic and non-economic costs (Fast et al., 1999), it has been argued that shifting care responsibilities from the state to the family would better be framed as cost redistribution than as cost-containment, and that policy makers should take into account the implications of informal care-giving for the lives of those engaged in it (Kotsadam, 2011; Van den Broek, 2013). The aim of the current study is to shed light on how the coverage of home-based LTC services may shape changes in quality of life that may occur when people become care providers for their ageing parents.

When care is more highly de-familialised, that is, when affordable statesupported care services are more widely available, there is arguably less pressure on family members to take on care tasks (Saraceno, 2010), and care-giving may thus be more a matter of choice. This may mean that any negative impacts of caregiving on wellbeing are less pronounced (Verbakel, 2014). Testing whether this is the case is a challenging affair, however. A common approach to estimate how the organisation of LTC shapes the impact of informal care-giving is to compare whether this impact varies between countries that have different LTC coverage, but this approach leaves considerable room for omitted variable bias. The country differences in LTC coverage often coincide with various other cultural, economic, demographic and policy differences between countries that may also influence the implications of informal care provision for people's lives. Consequently, it remains unclear what factors effectively drive country differences in the impact of informal care-giving.

As considered in further detail later, our approach differs from earlier work on the potential moderating impact of LTC coverage on the implications of informal care-giving. We use individual fixed-effects regression analyses to reduce omitted variable bias in the estimates of the effects of informal care-giving on care-givers' quality of life, ${ }^{1}$ and combine this with a difference-in-difference approach to reduce omitted variable bias in the estimated impact of LTC coverage on these effects. We draw on longitudinal data for Sweden and Denmark from the Survey of Health, Ageing and Retirement in Europe (SHARE) collected between 2004 and 2015. Both countries have traditionally tended to be presented as countries where the coverage of LTC services is markedly more generous than elsewhere in Europe (e.g. Anttonen and Sipilä, 1996). However, substantial cutbacks in LTC services were implemented at the end of the 20th century in Sweden and more recently in Denmark. We use this country difference in the timing of the LTC cutbacks to shed light on possible effects of the availability of state-supported LTC services on the impact of care-giving on quality of life.

\section{Care for older people in Sweden and Denmark}

Sweden and Denmark were among the first countries in Europe to recognise the need for LTC as a social risk requiring welfare state intervention (Österle and Rothgang, 2010). In the middle of the 20th century, both countries adopted a universalistic LTC system centred on the wide availability of affordable, state-supported services for all residents in need of care (Österle and Rothgang, 2010; Colombo, 
2012). Early care regime typologies, most of which drew on data from the 1980 s and 1990s, usually clustered Sweden and Denmark together and presented them as being among the countries where the coverage of care services was the most generous in Europe (Anttonen and Sipilä, 1996; Leitner, 2003; Bettio and Plantenga, 2004). Anttonen and Sipilä (1996) speak of a Scandinavian model of public services.

Rauch (2007), however, questioned whether such a categorisation was still appropriate for Sweden by the early 21st century. With the 1992 Ädel reform, the responsibility of Swedish municipalities for the provision of LTC was expanded. Municipalities had to take over the responsibility for patients treated in hospital within three days after they had been assessed as being well enough to be discharged, with non-compliant municipalities having to pay high hospital fees as a penalty (Lofgren, 2002). The Ädel reform meant that increasing numbers of older people with high care needs turned to Swedish municipalities whose budgets were already strained (Meagher and Szebehely, 2013). Given that rules about entitlement to care services were weaker in Sweden than in Denmark, Swedish municipalities could be increasingly restrictive with regard to the provision of care services, whereas Danish municipalities were prevented from doing this (Rauch, 2008). In Sweden, care services were increasingly targeted at those in the most severe need and co-payments from persons with less-severe care needs were increased (Sundström and Johansson, 2005; Pavolini and Ranci, 2008; Johansson et al., 2011). Consequently, older Swedes became less likely to receive state-supported home care services between the late 1990s and the early 2000s, and this could not be accounted for by improved health status of the later cohorts of older people (Larsson, 2006; cf. Meagher and Szebehely, 2013). In Denmark, in contrast, coverage levels and eligibility criteria for home-based LTC services remained largely unchanged (Rauch, 2008; Burau and Dahl, 2013).

More recently, LTC provision in Denmark and Sweden has become more similar again, albeit in a markedly different way than in the 1980s. Following Sweden, Denmark also started to move away from the ideal-type of the Scandinavian model of public services as described by Anttonen and Sipilä (1996). Recent changes in LTC coverage have been more pronounced in Denmark than in Sweden. Szebehely and Meagher (2018: 4) noted that Danish municipalities 'started to interpret the (unchanged) legislation in a more restrictive way'. They were further encouraged to do so by a 2011 court ruling confirming that under specific circumstances municipalities had the right to stop providing home care services to older persons who previously received home care, but no longer met tightened eligibility criteria (Szebehely and Meagher, 2018: 4). In contrast, Sweden has recently seen a slight increase in home care coverage, although this is likely related to continuing de-institutionalisation, i.e. an increased emphasis on home-based care services rather than on care provided in institutions, which resulted in strong declines in the availability of beds in residential care settings in Sweden (Ulmanen and Szebehely, 2015; Szebehely and Meagher, 2018). Similar declines in the availability of residential care took place in Denmark and other Nordic countries (Szebehely and Meagher, 2018).

The impact of the changes in home care coverage is evident in the proportions of older people receiving home-based LTC services. As shown in Figure 1, Organisation for Economic Co-operation and Development data indicate that 


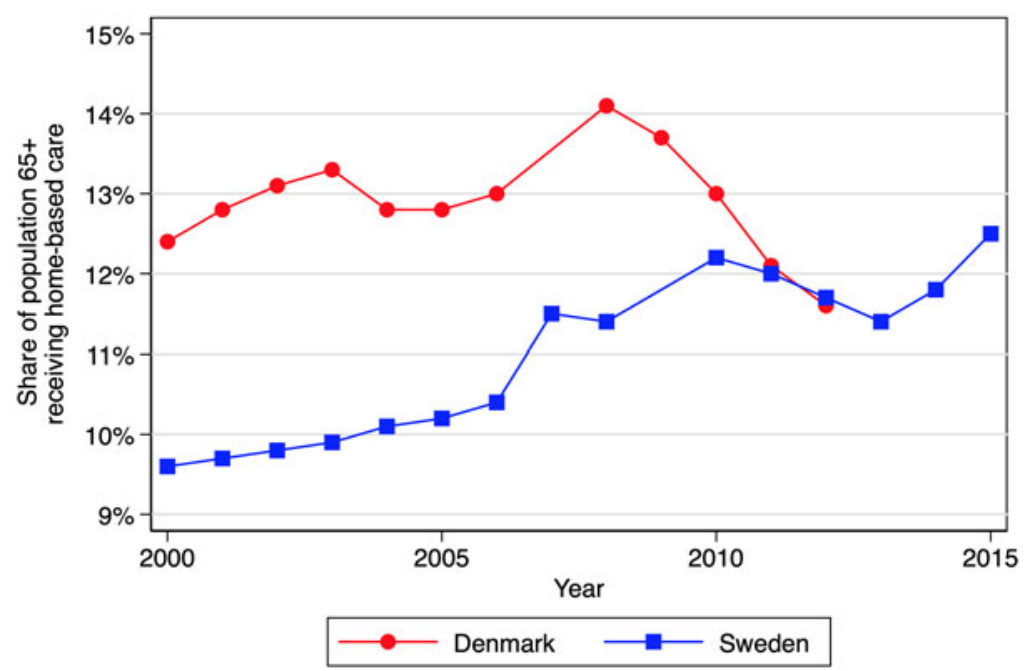

Figure 1. Home care services utilisation.

Source: Organisation for Economic Co-operation and Development Health Indicators: long-term care resources and utilisation; long-term care recipients at home. See https://stats.oecd.org/index.aspx?DataSetCode=HEALTH_LTCR.

utilisation of formal home care services (either publicly or privately financed) among the population aged 65 and older was around 3 percentage points higher in Denmark than in Sweden around the year 2000. Twelve years later, however, the country difference had disappeared. ${ }^{2}$

\section{Theoretical background and hypotheses}

Although providing care to ageing parents can be rewarding (Cohen et al., 2002), it is also potentially stressful. Care-giving stress may stem directly from the care recipients' health limitations and the extent and type of care needed, as well as indirectly through intra-psychic strains caused by changes in the care-giver's selfperception or through conflicts that may arise between care-giving and, for instance, other family or work responsibilities (Pearlin et al., 1990). Given that stress is known to be detrimental for quality of life (Litzelman et al., 2014), we expect that becoming a care-giver for ageing parents is negatively associated with quality of life (Hypothesis 1).

Research suggests that informal care-giving is particularly detrimental for wellbeing when care-givers perceive a lack of choice in taking on the care-giving role (Schulz et al., 2012). Pearlin et al. (1990) argued that so-called role captivity, i.e. the feeling of being compelled to engage in care-giving against one's will, is an important source of care-giver stress. Consistent with this reasoning, previous research has shown that care-givers report relatively high levels of anxiety and depressive symptoms when they resent having to care for a frail older relative (Aggar et al., 2011).

The extent to which the decision to take on care tasks is a matter of choice is arguably partly dependent on how LTC is organised. Leitner's (2003) typology of 
care systems is useful here. She distinguished countries by the extent to which they provide services that relieve families of the need to provide care to relatives and by the extent to which they support care-giving family members. Care-giving is assumed to be least burdensome in countries in the so-called optional familialism cluster and most burdensome in countries in the so-called implicit familialism cluster. In the former cluster, people are not strongly pressed to provide care to relatives in need, because state-supported LTC services are widely available, and those who choose to take on the care-giver role are supported, for instance through the availability of care leave arrangements, pension rights and/or cash benefits. In the latter cluster the situation for family members of older persons with care needs is the exact opposite. Here, LTC services coverage is low, effectively leaving the family few options but to take on caring responsibilities. Moreover, policies supporting family members engaged in the provision of care are lacking.

Drawing on data from the 1990s, Leitner (2003) placed both Denmark and Sweden in the optional familialism cluster. However, as described earlier, already by the early 2000s Sweden had moved away from the optional familialism way of organising LTC, given the country's cutbacks in LTC services in the 1990s (Rauch, 2007; Rostgaard and Szebehely, 2012). In the early 2000s, coverage of statesupported home care services was more extensive in Denmark than in Sweden (Rauch, 2007; Saraceno, 2010; Rostgaard and Szebehely, 2012). This may have made care-giving more a matter of choice and consequently potentially less stressful in the former country than in the latter. Also, care-giving adult children may provide care less frequently (Schmid et al., 2012) or take on less onerous care tasks (Brandt et al., 2009) when care-giving responsibilities can be shared with formal care-givers. We therefore expect any negative association between becoming a care-giver for ageing parents and quality of life to be stronger in Sweden than in Denmark (Hypothesis 2).

As described earlier, Szebehely and Meagher (2018) showed that the move away from the optional familialism ideal type as formulated by Leitner (2003) in Sweden mainly took place in the 1990s and stagnated around the turn of the century. In Denmark, in contrast, cutbacks in care services, and thus a move away from optional familialism, were only implemented more recently. This suggests that differences between Denmark and Sweden in the extent to which care-giving can be perceived as a matter of choice may have shrunk, which, in turn, leads us to hypothesise that the difference between both countries in the impact of the transition to the care-giver role on quality of life has become smaller over the course of the 21st century (Hypothesis 3).

\section{Data}

\section{Sample}

This study draws on data from Waves 1, 2, 4, 5 and 6 of SHARE (Börsch-Supan et al., 2013). SHARE is a longitudinal, cross-national data-set on the health, socioeconomic status and social relations of older Europeans. Data collection for the waves used in the current study took place in 2004-2005 (Wave 1), 2006-2007 (Wave 2), 2011 (Wave 4), 2013 (Wave 5) and 2015 (Wave 6). We limited our 
sample to Swedish and Danish men and women aged 50-75 who had at least one living parent in both Waves 1 and 2 or in both Waves 4 and 5 or in both Waves 5 and 6. For each respondent in our sample we thus have two observations. These selection criteria resulted in a sample of 5,450 observations nested in 2,725 women and men. Supplied calibrated longitudinal weights were used to adjust for bias arising from non-response and attrition. ${ }^{3}$ There were 454 respondents present in multiple sub-samples (Waves 1-2; Waves 4-5; Waves 5-6). We treated them as different persons and estimated all models with robust standard errors. ${ }^{4}$

\section{Measures}

Quality of life, i.e. 'the degree to which human needs are satisfied' (Hyde et al., 2003: 187), was measured with the CASP-12 instrument. CASP-12 is a shortened version of the validated CASP-19 measure of quality of life developed by Hyde et al. (2003) and captures four sub-dimensions of quality of life: control (C), autonomy (A), self-realisation (S) and pleasure (P). Each item of the CASP-12 consists of a statement about respondents' current lives or feelings, and respondents were asked to answer how often, if at all, the statement applied to them on a four-point scale ranging from 'never' to 'often'. ${ }^{5}$ A summed scale ranging from 12 to 48 was generated, with higher scores indicating better quality of life. In line with what has been reported in earlier work using the CASP-12 measure (Von dem Knesebeck et al., 2007), a reliability test indicated that the internal consistency of the shortened version of CASP was high in our sample (Cronbach's $\alpha=0.79$ ).

Care provision to parents was measured with a dichotomous variable capturing whether or not the respondent reported having provided personal care or practical household help to a father and/or mother in less than good health during the last 12 months. Parental fair or poor health was included as a condition to acknowledge what Walker et al. (1995) call the criterion of dependence, i.e. the notion that assistance can only be labelled care as opposed to aid when the recipient is unable to perform autonomously the everyday task for which support is received. This implies that older parents can only receive informal care when they have functional limitations. Unfortunately, information on whether or not respondents' parents had functional limitations was not available in our data, so we had to use the child's report that the parent's health was 'poor' or 'fair' as opposed to 'good', 'very good' or 'excellent' as a proxy for parental functional limitations. When respondents provided care at the first observation, but not at the second observation, they were coded as ex-care-givers, rather than as non-care-givers at the second observation. In selected analyses, we distinguished between sporadic and frequent care provision. Care to ageing parents was coded as frequent when respondents reported that they provided it 'about daily' or 'about every week' and as sporadic when care was provided less often.

In all models we included a range of time-varying control variables (age, partnership status and employment status) known to be associated with the likelihood of becoming a care-giver (Haberkern and Szydlik, 2010; Leopold et al., 2014; Van den Broek and Dykstra, 2017; Van den Broek et al., 2019), as well as with quality of life and mental wellbeing (Zaninotto et al., 2009; Jivraj et al., 2014; Gibney et al., 2017; Grundy et al., 2017). We distinguished five age groups: (a) 50-54 years old, 
(b) 55-59 years old, (c) 60-64 years old, (d) 65-69 years old and (e) 70-75 years old. Partnership status was measured with a dummy variable that distinguished between respondents who lived with a partner and their counterparts who did not. Employment status was measured with a dummy variable distinguishing respondents who reported that their current situation was best described as 'employed or self-employed (including working for family business)', rather than 'retired', 'unemployed', 'permanently sick or disabled', 'homemaker' or 'other'.

We also included a dichotomous variable distinguishing adult children with both parents still alive from those who had only one living parent. We did so, because when both parents are still alive and together, the other partner is typically first in line to take on care tasks (Shanas, 1979; Messeri et al., 1993; Jacobs et al., 2018), and parental loss is associated with declines in the mental wellbeing of adult children (Scharlach and Fredriksen, 1993; Leopold and Lechner, 2015).

Our definition of care-giving requires that the parent to which the child provides assistance is in less than good health, and several studies have shown that parental health limitations are associated with poorer mental wellbeing of their children, regardless of whether or not care is provided to the parent (Amirkhanyan and Wolf, 2006; Wolf et al., 2015; Van den Broek and Grundy, 2018). We therefore included a dummy variable indicating that at least one living parent reportedly had 'fair' or 'poor' health, as opposed to 'excellent', 'very good' or 'good' health.

Two observations were available for every respondent in our sample. We included a dichotomous variable to distinguish between first observations and second observations.

\section{Missing values}

In our sample, 1,231 observations $(22.6 \%)$ had missing values on at least one variable of interest: CASP-12 $(\mathrm{N}=281)$, care-giver status $(\mathrm{N}=806)$, parental health limitations $(\mathrm{N}=151)$ or employment status $(\mathrm{N}=23)$. Values on our quality of life measure, CASP-12, were particularly likely to be missing in Wave $1(\mathrm{~N}=$ 212), when the items were collected as part of the individual paper questionnaire, rather than as part of the computer-assisted personal interviews. Wave $4(\mathrm{~N}=189)$ and Wave $5(\mathrm{~N}=613)$ had large numbers of missing values on care-giver status. This was because in these waves questions about informal care-giving were only asked of so-called family respondents.

To deal with this missing information, we used multiple imputation with chained equations under the missing at random assumption (Young and Johnson, 2015). This means that we assume that any differences between the distributions of missing values and the distributions of observed values can be explained by variables included in the imputation model (Bhaskaran and Smeeth, 2014). Imputations were conducted in wide data format (cf. Young and Johnson, 2015). Separate imputation models were estimated by country and period. Time-invariant ancillary variables included in the imputation models were gender, number of siblings, number of children and educational attainment measured at baseline. Education was measured with a categorical variable, whereby we distinguished low (International Standard Classification of Education (ISCED) 0-2; preprimary to lower secondary education), medium (ISCED 3-4; upper secondary to 
post-secondary non-tertiary education) and high (ISCED 5-6; tertiary education) levels of educational attainment. The findings from the substantive analyses on 20 imputed data-sets were combined into a single set of results following Rubin's rules (Little and Rubin, 1989), which take the variability in results between the imputed data-sets into account.

\section{Method}

We estimated fixed-effects linear regression models to study intra-individual change in mid-life persons' quality of life. We started by estimating a straightforward model, such as depicted in Equation (1):

$$
\ddot{y}_{i t}=\beta_{1} \ddot{S}_{i t}+\beta_{2} \ddot{X}_{i t}+\ddot{e}_{i t}
$$

Where

$$
\begin{gathered}
\ddot{y}_{i t}=y_{i t}-\bar{y}_{i} \\
\ddot{S}_{i t}=S_{i t}-\bar{S}_{i} \\
\ddot{X}_{i t}=X_{i t}-\bar{X}_{i} \\
\ddot{e}_{i t}=e_{i t}-\bar{e}_{i}
\end{gathered}
$$

Equations (2)-(5) indicate that for the outcome variable $y$ (quality of life), main explanatory variable $S$ (care-giver status), time-varying covariates $X$ and the error term $e$, we deducted the mean score for individual $i$ over both time-points from the score for individual $i$ on time-point $t$. This procedure implies that we regressed temporal variation in quality of life within individuals on within-individual change in care-giver status and the control variables. Consequently, all time-invariant characteristics, including those not observed, were accounted for (Allison, 2009). This makes our estimates of the effects of providing care to ageing parents on quality of life not prone to bias due to omitted variables that are constant over time (Taylor et al., 1995; Kaschowitz and Brandt, 2017; Van den Broek and Grundy, 2018).

To test whether the association between providing care to ageing parents and quality of life was more strongly negative in Sweden than in Denmark, we estimated a model in which we allowed the effect of the transition to the role of care provider to vary by country $C$ (Denmark versus Sweden), which is time invariant.

$$
\ddot{y}_{i t}=\beta_{1} \ddot{S}_{i t}+\beta_{2} \ddot{X}_{i t}+\beta_{3} C_{i} \ddot{S}_{i t}+\ddot{e}_{i t}
$$

In the final model, we combined the fixed-effects approach with a difference-in-difference strategy. The effect of change in care-giver status on change in quality of life 
was allowed to vary not only as a function of country $C$, but also as a function of period $P$ (2011-2015 versus 2004-2007, also time invariant) and as a function of the interaction between the two:

$$
\ddot{y}_{i t}=\beta_{1} \ddot{S}_{i t}+\beta_{2} \ddot{X}_{i t}+\beta_{3} C_{i} \ddot{S}_{i t}+\beta_{4} P_{i} \ddot{S}_{i t}+\beta_{5} C_{i} P_{i} \ddot{S}_{i t}+\ddot{e}_{i t}
$$

where $\beta_{5}$ denotes the estimates in which we are most interested. It captures the estimated change over the two considered time periods in the difference between the two considered countries in the effect of change in care-giver status on change in quality of life. This approach leaves less room for bias in the estimates of the moderating effects of contextual factors due to the presence of omitted higher-level confounding factors than is the case in country comparisons at a single point in time (or multiple, pooled time-points), commonly used in previous studies. In traditional country comparisons, any omitted variable associated with the country-level moderator variable of interest - in our case LTC coverage - may be a confounder of the estimated moderating effect. In our approach, country characteristics omitted from the model as moderator variables can only lead to biased estimates if they develop differently in Sweden and Denmark over the considered time-frame ( $c f$. Angrist and Pischke, 2009; Lechner, 2011). Omitted country characteristics that are constant over time or that vary similarly over time in both countries may influence the estimated stable country differences in the impact of change in care-giver status on change in quality of life $\left(\beta_{3}\right)$, but not our main coefficients of interest $\left(\beta_{5}\right)$. All models were estimated with robust standard errors (White, 1980).

\section{Results}

Descriptive results are presented in Table 1. Quality of life was higher among members of the Danish than the Swedish sample $(F(1,5448)=85.4, p<0.001)$. Although coverage of state-supported home care services was more extensive in Denmark than in Sweden for most of the period studied, the proportion of adult children providing care to ageing parents did not differ substantially between countries (cf. Verbakel et al., 2017). Also, the share of respondents that made a transition from non-care-giver to care-giver or from care-giver to ex-care-giver did not vary substantially across the two countries (see Appendix A in the online supplementary material).

Results of our fixed-effects regression analyses of quality of life are presented in Table 2. Consistent with our first hypothesis, the first model shows that starting to provide care to ageing parents was associated with a reduction in quality of life. Possibly because it may take time to recover from the hardships associated with care-giving, transition from care-giver to ex-care-giver was not associated with a significant increase in quality of life $(\Delta b=0.46, p=0.30){ }^{6}$ Being in the 60-64 or the 65-69 age group, as opposed to the 50-54 age group, was associated with better quality of life. No significant effects were found for any of the other explanatory variables included in the model.

In the second model, we allowed the effects of care-giver status transitions to differ between Denmark and Sweden by adding an interaction term. The model shows 
Table 1. Sample characteristics

\begin{tabular}{|c|c|c|}
\hline Variable & Sweden & Denmark \\
\hline \multicolumn{3}{|l|}{ CASP-12: } \\
\hline Mean score & 40.0 & 41.2 \\
\hline \multirow[t]{2}{*}{ Standard deviation } & 4.9 & 4.5 \\
\hline & \multicolumn{2}{|c|}{ Percentages } \\
\hline \multicolumn{3}{|l|}{ Care-giver status: } \\
\hline Non-care-giver & 75.2 & 74.2 \\
\hline Current care-giver (sporadic or frequent) & 21.3 & 21.4 \\
\hline Sporadic care-giver & 12.9 & 12.2 \\
\hline Frequent care-giver & 8.3 & 9.1 \\
\hline Ex-care-giver & 3.5 & 4.4 \\
\hline \multicolumn{3}{|l|}{ Gender: } \\
\hline Female & 49.6 & 50.0 \\
\hline Male & 50.4 & 50.0 \\
\hline \multicolumn{3}{|l|}{ Age: } \\
\hline $50-54$ & 26.4 & 31.8 \\
\hline $55-59$ & 41.7 & 37.5 \\
\hline $60-64$ & 21.7 & 21.1 \\
\hline $65-69$ & 8.3 & 8.2 \\
\hline $70-75$ & 1.9 & 1.3 \\
\hline Lives with partner & 69.5 & 77.4 \\
\hline Employed & 78.3 & 70.5 \\
\hline One parent deceased & 73.8 & 77.7 \\
\hline At least one parent with less than good health & 55.9 & 47.6 \\
\hline Respondent has less than good health & 14.2 & 15.5 \\
\hline \multicolumn{3}{|l|}{ Period: } \\
\hline Waves 1-2 (2004-2007) & 33.8 & 34.1 \\
\hline Waves 4-6 (2011-2015) & 66.2 & 65.9 \\
\hline Observations & 2,626 & 2,824 \\
\hline Persons & 1,313 & 1,412 \\
\hline
\end{tabular}

Notes: Multiple imputation using chained equations was used to deal with missing values. Data are weighted. Source: Survey of Health, Ageing and Retirement in Europe (SHARE), Waves 1, 2, 4, 5 and 6.

a marked negative effect of care provision on quality of life in Sweden. The significant interaction term (current care-giver $\times$ Denmark) indicates support for our second hypothesis: the negative effect of becoming a care-giver was markedly weaker in Denmark than in Sweden. The effect of care provision was in fact not statistically significant in Denmark $(b=0.30, p=0.84)$. 
Table 2. Results of fixed-effects regression analyses of quality of life (CASP-12)

\begin{tabular}{|c|c|c|c|c|c|c|}
\hline \multirow[b]{2}{*}{ Variables } & \multicolumn{2}{|c|}{ Model 1} & \multicolumn{2}{|c|}{ Model 2} & \multicolumn{2}{|c|}{ Model 3} \\
\hline & B & SE & B & SE & $B$ & SE \\
\hline Non-care-giver & Ref. & & Ref. & & Ref. & \\
\hline Current care-giver & $-0.62^{\star}$ & 0.29 & $-1.11^{\star *}$ & 0.37 & & \\
\hline Current care-giver (sporadic) & & & & & $-1.06^{\star *}$ & 0.39 \\
\hline Current care-giver (frequent) & & & & & $-1.24^{\star}$ & 0.49 \\
\hline Ex-care-giver & -0.16 & 0.53 & -0.48 & 0.74 & -0.49 & 0.73 \\
\hline Current care-giver $\times$ Denmark & & & $1.40^{\star *}$ & 0.44 & & \\
\hline Current care-giver (sporadic) $\times$ Denmark & & & & & $1.43^{\star \star}$ & 0.49 \\
\hline Current care-giver (frequent) $\times$ Denmark & & & & & $1.44^{\star}$ & 0.60 \\
\hline Ex-care-giver $\times$ Denmark & & & 0.96 & 0.83 & 0.99 & 0.83 \\
\hline Follow-up & 0.22 & 0.15 & 0.22 & 0.15 & 0.22 & 0.15 \\
\hline \multicolumn{7}{|l|}{ Age: } \\
\hline $50-54$ & Ref. & & Ref. & & Ref. & \\
\hline $55-59$ & 0.39 & 0.34 & 0.38 & 0.34 & 0.38 & 0.34 \\
\hline $60-64$ & $1.16^{\star}$ & 0.48 & $1.14^{\star}$ & 0.48 & $1.14^{\star}$ & 0.48 \\
\hline $65-69$ & $1.52^{\star}$ & 0.65 & $1.53^{\star}$ & 0.64 & $1.54^{\star}$ & 0.64 \\
\hline $70-75$ & 1.09 & 1.09 & 1.12 & 1.08 & 1.12 & 1.08 \\
\hline Lives with partner & -0.57 & 0.56 & -0.55 & 0.56 & -0.54 & 0.56 \\
\hline Employed & 0.33 & 0.34 & 0.35 & 0.34 & 0.34 & 0.34 \\
\hline One parent deceased & -0.18 & 0.46 & -0.18 & 0.46 & -0.18 & 0.46 \\
\hline $\begin{array}{l}\text { At least one parent with less than good } \\
\text { health }\end{array}$ & -0.11 & 0.25 & -0.13 & 0.25 & -0.12 & 0.25 \\
\hline
\end{tabular}

Notes: $\mathrm{N}=5,450$. Multiple imputation using chained equations was used to deal with missing values. Data are weighed. SE: robust standard errors. Ref.: reference category.

Source: Survey of Health, Ageing and Retirement in Europe (SHARE), Waves 1, 2, 4, 5 and 6.

Significance levels: * $p<0.05,{ }^{\star *} p<0.01$.

In an additional model (not shown in Table 2; see Appendix B in the online supplementary material), we included two three-way interaction terms (current caregiver $\times$ country $\times$ period; ex-care-giver $\times$ country $\times$ period) to test whether the country differences in the effects of care provision have become smaller over time. Figure 2 shows the size of the estimated effect of a transition to care-giving on quality of life by country and period based on the three-way interaction model. The figure shows convergence over time between Sweden and Denmark in the impact of becoming a care-giver. The estimated effect of becoming a caregiver was more strongly negative in Sweden than in Denmark $(b=-2.59, p<$ 0.01 ) in the 2004-2007 period. In the 2011-2015 period (Waves 4-6), the country difference in the estimated effect was smaller and no longer statistically significant 


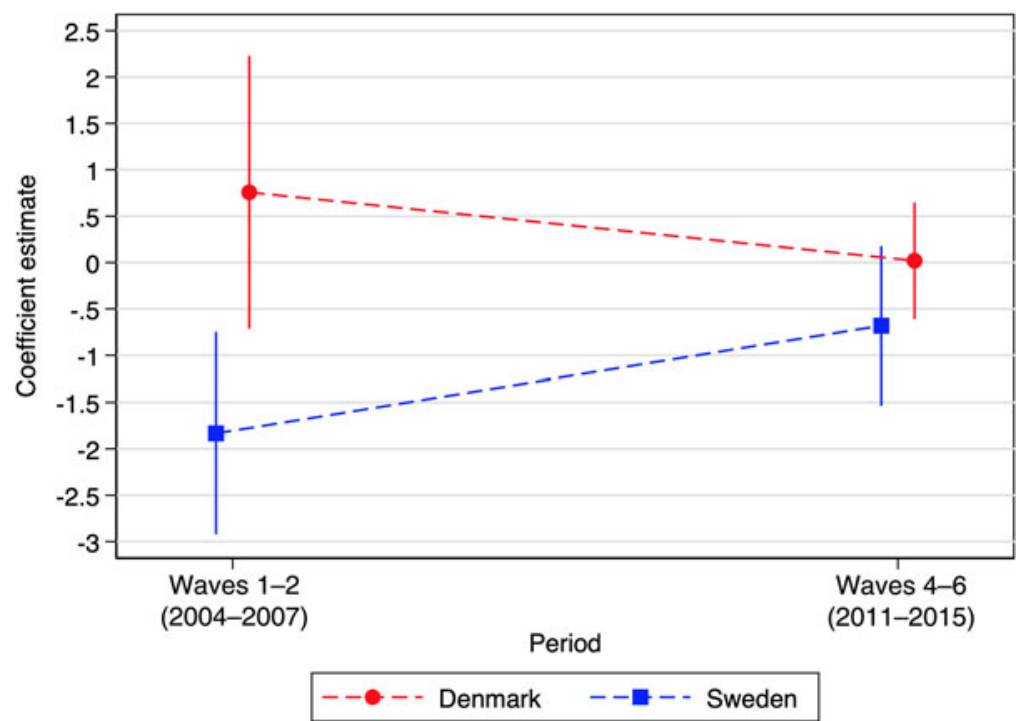

Figure 2. Estimated impact of care provision to ageing parents on quality of life.

Note: Estimated effect of current caregiver by country and period, based on model with three-way interaction terms (See Appendix B in the online supplementary material).

$(\Delta b=-0.70, p=0.13)$. The difference-in-difference estimate, i.e. the change between Period 1 (2004-2007) and Period 2 (2011-2015) in the country difference in the estimated effect of becoming a care-giver on quality of life, was statistically significant $(\Delta \Delta b=1.89, p<0.05)$. This is consistent with our third hypothesis that the difference between Sweden and Denmark in the effect of providing care to ageing parents on quality of life was smaller in the 2011-2015 period than in the 2004-2007 period, and suggests that LTC coverage shapes the impact of informal care-giving on quality of life.

Given that the frequent provision of care might be more burdensome and so more detrimental for quality of life than sporadic provision of care ( $c f$. Pinquart and Sörensen, 2003; Verbakel et al., 2017), we distinguished between at least weekly care provision and less frequent provision of care in Model 3 (see Table 2). However, the differences between frequent and sporadic care provision in the estimated impact on quality of life were negligible and not statistically significant in either Sweden $(\Delta b=-0.18, p=0.70)$ or Denmark $(\Delta b=-0.16, p=0.71)$.

In the models presented here, we did not adjust for respondents' own health, because this arguably could be considered a so-called 'bad control'. Research suggests that providing informal care can be detrimental for adult children's own health (Coe and Van Houtven, 2009), and this may, in turn, result in declines in quality of life. Adjusting for respondents' own health may thus lead to underestimation of the full effect of informal care provision. However, own poor health may also be a reason for not taking on care tasks. As a robustness check, we therefore re-estimated Models 1-3, additionally adjusting for respondents' own health measured with a dichotomous variable for 'fair' or 'poor' versus 'excellent', 'very good' or 'good' self-reported overall health. These models (full results available 
on request) show that a transition from good to less than good self-rated health was associated with a marked decline in quality of life. The estimates of effects of becoming a care-giver did not change substantially, however, after the addition to the models of respondents' own self-rated health. This suggests that mechanisms other than care-giving-induced declines in adult children's own self-rated health underlie the detrimental effect of becoming a care-giver on quality of life.

In the models presented in Table 2, the effects of care-giving on quality of life were constrained to be similar for men and women. We re-estimated these models, allowing the effects of care-giving and, in Models 2 and 3, the country differences in these effects to vary by gender (not shown in Table 2; full results available on request), to test whether it was problematic to assume the absence of gender differences in the impact of care-giving on quality of life. These additional analyses did not provide evidence that this was the case, as Wald tests indicated that neither the addition of a gender interaction (care-giver status $\times$ gender) to Model 1 , nor the addition of three-way interaction terms to Model 2 or Model 3, was statistically significant.

\section{Discussion}

When affordable state-supported care services are more widely available, there is arguably less pressure on family members to provide care to ageing relatives with health limitations, which may mean that care-giving has less of an impact on caregivers' wellbeing. In the current study, we investigated the impact of providing care to ageing parents on adult children's quality of life in Sweden and Denmark. Both countries were traditionally characterised by generous LTC coverage, but in the 1990s in Sweden and more recently in Denmark there has been substantial retrenchment of provision.

Our approach differs from earlier studies on the ways in which LTC coverage might shape the implications of informal care-giving. Often, the effects of formal LTC arrangements on the impact of care-giving on wellbeing and quality of life are analysed using country comparisons at a single point in time, or at multiple, pooled time-points. In such an approach it is assumed that in the absence of the difference in the way LTC is organised, the effects of care-giving on wellbeing and quality of life would be identical across countries. This is a rather bold assumption, given that country differences in LTC policy arrangements often coincide with various cultural, economic, demographic and policy differences between countries that may also influence the implications of informal care provision for people's lives. Verbakel (2014: 426), who showed that the difference in happiness between people who provided informal care and people who did not was smaller in countries with more generous formal LTC resources, acknowledged that she could 'not be conclusive regarding whether it is truly the national policy measure that reduces negative well-being consequences of informal caregiving'. We used individual fixed-effects regression analyses to reduce omitted variable bias in the estimates of the effects of informal care-giving, and combine this with a difference-indifference approach to reduce omitted variable bias in the estimated impact of LTC coverage on these effects. Consequently, our assumptions when estimating the impact of LTC coverage on the implications of care-giving are relatively 
weak: we assume that in the absence of country differences in the change in LTC coverage, the difference between Sweden and Denmark in the effect of change in care-giver status on quality of life would be constant across periods.

As hypothesised, our analyses show that care-giving was more detrimental for quality of life in Sweden than in Denmark. In fact, no significant impact of caregiving on quality of life was found in Denmark. Moreover, we showed that the country difference in the effect of care-giving on quality of life weakened significantly when LTC coverage was reduced in Denmark, but not in Sweden. Given the relatively weak assumptions underlying our analyses, this result provides evidence that LTC coverage shapes the impact of care-giving on quality of life.

It should be noted that we had to use a somewhat crude measure of care provision. In selected analyses, we distinguished between care provided at least weekly and care provided less often. We could not, however, take into account the time spent on care-giving, because this information was not collected in Waves 4-6 of SHARE. This is unfortunate, because research has shown that care-giving is considered more burdensome when more hours per week are spent on care-giving (Pinquart and Sörensen, 2003). Also, we could not distinguish between household chores, such as cleaning the house and grocery shopping, and personal care tasks, such as help with bathing or dressing. This is because in Waves 4 and 5 of SHARE the question about the types of assistance was omitted. Given that the latter tasks are more intensive and less routine than the former (Walker et al., 1995), they may also be more detrimental for quality of life. Furthermore, our difference-indifference approach was based on aggregate trends of LTC coverage in Sweden and Denmark, with substantial cutbacks occurring in the 1990s in the former country and more recently in the latter country. Given the autonomy of municipalities, particularly in Sweden, local deviations from these aggregate trends are likely. However, reliable time-series data at the municipality level is, to our best knowledge, not available (cf. Schön and Johansson, 2016).

The current study may also be relevant for researchers interested in topics other than LTC, informal care-giving or intergenerational support exchanges. The fact that the small number of countries available in most cross-national data-sets limits the number of cross-level interaction terms that can be included in statistical models is a problem with which scholars interested in a wide range of different topics have been grappling. For some of these scholars, our approach of combining fixed-effects analyses with a difference-in-difference approach may provide a useful blueprint of how the impact of a country characteristic on the implications of a transition from one state to another at the individual level could be modelled in a way that limits room for omitted variable bias.

Supplementary material. The supplementary material for this article can be found at https://doi.org/10. 1017/S0144686X18001708.

Data. This paper uses data from SHARE Waves 1, 2, 4, 5 and 6 (DOIs: 10.6103/SHARE.w1.600, 10.6103/ SHARE.w2.600, 10.6103/SHARE.w5.600, 10.6103/SHARE.w6.600), see Börsch-Supan et al. (2013) for methodological details. The SHARE data collection has been primarily funded by the European Commission through FP5 (QLK6-CT-2001-00360), FP6 (SHARE-I3: RII-CT-2006-062193, COMPARE: CIT5-CT-2005-028857, SHARELIFE: CIT4-CT-2006-028812) and FP7 (SHARE-PREP: No. 211909, SHARE-LEAP: No. 227822, SHARE M4: No. 261982). Additional funding from the German Ministry of 
Education and Research, the Max Planck Society for the Advancement of Science, the US National Institute on Aging (U01_AG09740-13S2, P01_AG005842, P01_AG08291, P30_AG12815, R21_AG025169, Y1-AG-4553-01, IAG_BSR06-11, OGHA_04-064, HHSN271201300071C) and from various national funding sources is gratefully acknowledged (see www.share-project.org).

Financial support. The research leading to these results has received funding from the European Research Council under the European Union's Seventh Framework Programme (FP7/2007-2013)/ERC Grant Agreement No. 324055 (FAMHEALTH).

Ethical standards. Not applicable.

\section{Notes}

1 As considered in further detail later, however, fixed-effects models only eliminate bias due to omitted variables fixed in time.

2 Slightly different data about home care coverage from the national statistical offices of Sweden and Denmark between 2000 and 2015 are presented by Szebehely and Meagher (2018) and the Nordic Social Statistical Committee (NOSOSCO) (2016: 168). Although their data suggest that home care services coverage remains somewhat more generous in Sweden than in Denmark in 2015, they also show a clear trend of convergence between both countries in the period 2000-2015, with stable (NOSOSCO, 2016) or even slightly increasing (Szebehely and Meagher, 2018) coverage in Sweden and marked declines in coverage from 2008 onwards in Denmark.

3 These weights make the respondents who were present in both Waves 1 and 2 representative of the 50+ population of 2005 (when Wave 1 data were collected) who survived until 2007 (when Wave 2 data were collected). After weighting, respondents who were present in both Waves 4 and 5 (regardless of whether they were members of the refreshment sample or of earlier baseline samples) were representative of the $50+$ population in 2011 (when Wave 4 data were collected) who survived until 2013 (when Wave 5 data were collected), and respondents who were present in both Waves 5 and 6 were representative of the 50 + population in 2013 (when Wave 5 data were collected) who survived until 2015 (when Wave 6 data were collected).

4 As a robustness check, we re-estimated all models, randomly dropping the observations from all but one period for the group included in multiple time periods (results are available upon request). All coefficient estimates were in the same direction. |With 1,226 observations fewer, statistical power was substantially smaller in this sample, however. Consequently, no support for Hypothesis 1 was found, but Hypothesis 2 was supported. Support for Hypothesis 3 was found, but only at a marginally significant alpha level of $\alpha=0.10$. 5 The 12 items of the CASP-12 scale were: 'How often do you think your age prevents you from doing the things you would like to do?', 'How often do you feel that what happens to you is out of your control?', 'How often do you feel left out of things?', 'How often do you think that you can do the things that you want to do?', 'How often do you think that family responsibilities prevent you from doing what you want to do?', 'How often do you think that shortage of money stops you from doing the things you want to do?', 'How often do you look forward to each day?', 'How often do you feel that your life has meaning?', 'How often, on balance, do you look back on your life with a sense of happiness?', 'How often do you feel full of energy these days?', 'How often do you feel that life is full of opportunities?' and 'How often do you feel that the future looks good for you?'

6 The differences in coefficient estimates presented at various points in this section are differences between the coefficient estimates of two non-reference categories reported in Table 2. These were obtained using the lincom post-estimation command in STATA 15.1.

\section{References}

Aggar C, Ronaldson S and Cameron ID (2011) Self-esteem in carers of frail older people: resentment predicts anxiety and depression. Aging \& Mental Health 15, 671-678.

Allison PD (2009) Fixed Effects Regression Models. Thousand Oaks, CA: Sage. 
Amirkhanyan AA and Wolf DA (2006) Parent care and the stress process: findings from panel data. Journals of Gerontology: Psychological Sciences and Social Sciences 61B, S248-S255.

Angrist JD and Pischke J-S (2009) Mostly Harmless Econometrics: An Empiricist's Companion. Princeton, NJ: Princeton University Press.

Anttonen A and Sipilä J (1996) European social care services: is it possible to identify models ? Journal of European Social Policy 6, 87-100.

Bettio F and Plantenga J (2004) Comparing care regimes in Europe. Feminist Economics 10, 85-113.

Bhaskaran K and Smeeth L (2014) What is the difference between missing completely at random and missing at random? International Journal of Epidemiology 43, 1336-1339.

Blomgren J, Breeze E, Koskinen S and Martikainen P (2012) Help from spouse and from children among older people with functional limitations: comparison of England and Finland. Ageing \& Society 32, 905933.

Börsch-Supan A, Brandt M, Hunkler C, Kneip T, Korbmacher J, Malter F, Schaan B, Stuck S and Zuber S (2013) Data resource profile: the Survey of Health, Ageing and Retirement in Europe (SHARE). International Journal of Epidemiology 42, 992-1001.

Brandt M, Haberkern K and Szydlik M (2009) Intergenerational help and care in Europe. European Sociological Review 25, 585-601.

Burau V and Dahl HM (2013) Trajectories of change in Danish long term care policies - reproduction by adaptation through top-down and bottom-up reforms. In Ranci C and Pavolini E (eds), Reforms in Long-term Care Policies in Europe. Investigating Institutional Change and Social Impacts. New York, NY: Springer, pp. 79-95.

Coe NB and Van Houtven CH (2009) Caring for mom and neglecting yourself? The health effects of caring for an elderly parent. Health Economics 18, 991-1010.

Cohen CA, Colantonio A and Vernich L (2002) Positive aspects of caregiving: rounding out the caregiver experience. International Journal of Geriatric Psychiatry 17, 184-188.

Colombo F (2012) Typologies of public coverage for long-term care in OECD countries. In Costa-Font J and Courbage C (eds), Financing Long-term Care in Europe. Institutions, Markets and Models. Basingstoke, UK: Palgrave Macmillan, pp. 17-40.

Fast JE, Williamson DL and Keating NC (1999) The hidden costs of informal elder care. Journal of Family and Economic Issues 20, 301-326.

Gibney S, Delaney L, Codd M and Fahey T (2017) Lifetime childlessness, depressive mood and quality of life among older Europeans. Social Indicators Research 130, 305-323.

Grundy E, Van den Broek T and Keenan K (2017) Number of children, partnership status, and later-life depression in Eastern and Western Europe. Journals of Gerontology: Psychological Sciences and Social Sciences. doi: 10.1093/geronb/gbx050.

Haberkern K and Szydlik M (2010) State care provision, societal opinion and children's care of older parents in 11 European countries. Ageing \& Society 30, 299-323.

Hyde M, Wiggins RD, Higgs P and Blane DB (2003) A measure of quality of life in early old age: the theory, development and properties of a needs satisfaction model (CASP-19). Aging \& Mental Health 7, 186-194.

Jacobs MT, Broese van Groenou MI, Aartsen MJ and Deeg DJH (2018) Diversity in older adults' care networks: the added value of individual beliefs and social network proximity. Journals of Gerontology: Psychological Sciences and Social Sciences 73, 326-336.

Jivraj S, Nazroo J, Vanhoutte B and Chandola T (2014) Aging and subjective well-being in later life. Journals of Gerontology: Psychological Sciences and Social Sciences 69B, 930-941.

Johansson L, Long H and Parker MG (2011) Informal caregiving for elders in Sweden: an analysis of current policy developments. Journal of Aging \& Social Policy 23, 335-353.

Kaschowitz J and Brandt M (2017) Health effects of informal caregiving across Europe: a longitudinal approach. Social Science \& Medicine 173, 72-80.

Kotsadam A (2011) Does informal eldercare impede women's employment? The case of European welfare states. Feminist Economics 17, 121-144.

Larsson K (2006) Care needs and home-help services for older people in Sweden: does improved functioning account for the reduction in public care? Ageing \& Society 26, 413-429.

Lechner M (2011) The estimation of causal effects by difference-in-difference methods. Foundations and Trends in Econometrics 4, 165-224. 
Leitner S (2003) Varieties of familialism: the caring function of the family in comparative perspective. European Societies 5, 353-375.

Leopold T and Lechner CM (2015) Parents' death and adult well-being: gender, age, and adaptation to filial bereavement. Journal of Marriage and Family 77, 747-760.

Leopold T, Raab M and Engelhardt $\mathbf{H}$ (2014) The transition to parent care: costs, commitments, and caregiver selection among children. Journal of Marriage and Family 76, 300-318.

Little RJA and Rubin DB (1989) The analysis of social science data with missing values. Sociological Methods \& Research 18, 292-326.

Litzelman K, Skinner HG, Gangnon RE, Nieto FJ, Malecki K and Witt WP (2014) Role of global stress in the health-related quality of life of caregivers: evidence from the Survey of the Health of Wisconsin. Quality of Life Research 23, 1569-1578.

Lofgren R (2002) The Swedish Health Care System: Recent Reforms, Problems, and Opportunities. Vancouver: Fraser Institute.

Meagher G and Szebehely M (2013) Long-term care in Sweden: trends, actors, and consequences. In Ranci C and Pavolini E (eds), Reforms in Long-term Care Policies in Europe. Investigating Institutional Change and Social Impacts. New York, NY: Springer, pp. 55-78.

Messeri P, Silverstein M and Litwak E (1993) Choosing optimal support groups: a review and reformulation. Journal of Health and Social Behavior 34, 122-137.

Nordic Social Statistical Committee (NOSOSCO) (2016) Social Protection in the Nordic Countries 2014/ 2015. Scope, Expenditure and Financing. Copenhagen: NOSOSCO.

Österle A and Rothgang H (2010) Long-term care. In Castles FG, Leibfried S, Lewis J, Obinger H, Pierson C, Österle A and Rothgang H (eds), The Oxford Handbook of the Welfare State. Oxford: Oxford University Press, 378-390.

Pavolini E and Ranci C (2008) Restructuring the welfare state: reforms in long-term care in Western European countries. Journal of European Social Policy 18, 246-259.

Pearlin LI, Mullan JT, Semple SJ and Skaff MM (1990) Caregiving and the stress process: an overview of concepts and their measures. The Gerontologist 30, 583-594.

Pinquart M and Sörensen S (2003) Associations of stressors and uplifts of caregiving with caregiver burden and depressive mood: a meta-analysis. Journals of Gerontology: Psychological Sciences and Social Sciences 58B, P112-P128.

Ranci C and Pavolini E (2015) Not all that glitters is gold: long-term care reforms in the last two decades in Europe. Journal of European Social Policy 25, 270-285.

Rauch D (2007) Is there really a Scandinavian social service model? A comparison of childcare and elderlycare in six European countries. Acta Sociologica 50, 249-269.

Rauch D (2008) Central versus local service regulation: accounting for diverging old-age care developments in Sweden and Denmark, 1980-2000. Social Policy \& Administration 42, 267-287.

Rostgaard T and Szebehely M (2012) Changing policies, changing patterns of care: Danish and Swedish home care at the crossroads. European Journal of Ageing 9, 101-109.

Saraceno C (2010) Social inequalities in facing old-age dependency: a bi-generational perspective. Journal of European Social Policy 20, 32-44.

Scharlach AE and Fredriksen KI (1993) Reactions to the death of a parent during midlife. OMEGA - Journal of Death and Dying 27, 307-319.

Schmid T, Brandt M and Haberkern K (2012) Gendered support to older parents: do welfare states matter? European Journal of Ageing 9, 39-50.

Schön P and Johansson L (2016) ESPN Thematic Report on Work-Life Balance Measures for Persons of Working Age with Dependent Relatives. Sweden 2016. Brussels: European Commission.

Schulz R, Beach SR, Cook TB, Martire LM, Tomlinson JM and Monin JK (2012) Predictors and consequences of perceived lack of choice in becoming an informal caregiver. Aging \& Mental Health 16, 712-721.

Shanas E (1979) The family as a social support system in old age. The Gerontologist 19, 169-174.

Silverstein M, Gans D and Yang FM (2006) Intergenerational support to aging parents: the role of norms and needs. Journal of Family Issues 27, 1068-1084.

Sundström G and Johansson L (2005) The changing balance of government and family in care for the elderly in Sweden and other European countries. Australasian Journal on Ageing 24, S5-S11.

Szebehely M and Meagher G (2018) Nordic eldercare - weak universalism becoming weaker? Journal of European Social Policy 28, 294-308. 
Taylor R, Ford G and Dunbar M (1995) The effects of caring on health: a community-based longitudinal study. Social Science \& Medicine 40, 1407-1415.

Ulmanen P and Szebehely M (2015) From the state to the family or to the market? Consequences of reduced residential eldercare in Sweden. International Journal of Social Welfare 24, 81-92.

Van den Broek T (2013) Formalization of informal care in the Netherlands: cost containment or gendered cost redistribution? International Journal of Feminist Approaches to Bioethics 6, 185-193.

Van den Broek T and Dykstra PA (2017) Residential care and care to community-dwelling parents: outselection, in-selection and diffusion of responsibility. Ageing \& Society 37, 1609-1631.

Van den Broek T, Dykstra PA and Van der Veen RJ (2019) Adult children stepping in? Long-term care reforms and trends in children's provision of household support to impaired parents in the Netherlands. Ageing \& Society 39, 112-137.

Van den Broek T and Grundy E (2018) Parental health limitations, caregiving and loneliness among women with widowed parents. Longitudinal evidence from France. European Journal of Ageing 15, 369-377.

Verbakel E (2014) Informal caregiving and well-being in Europe: what can ease the negative consequences for caregivers? Journal of European Social Policy 24, 424-441.

Verbakel E, Tamlagsrønning S, Winstone L, Fjær EL and Eikemo TA (2017) Informal care in Europe: findings from the European Social Survey (2014) special module on the social determinants of health. European Journal of Public Health 27, 90-95.

Von dem Knesebeck O, Wahrendorf M, Hyde M and Siegrist J (2007) Socio-economic position and quality of life among older people in 10 European countries: results of the SHARE study. Ageing \& Society 27, 269-284.

Walker AJ, Pratt CC and Eddy L (1995) Informal caregiving to aging family members: a critical review. Family Relations 44, 402-411.

White H (1980) A heteroskedasticity-consistent covariance matrix estimator and a direct test for heteroskedasticity. Econometrica 48, 817-838.

Wolf DA, Raissian KM and Grundy E (2015) Parental disability, parent care, and offspring mental health outcomes. European Journal of Ageing 12, 175-185.

Young R and Johnson DR (2015) Handling missing values in longitudinal panel data with multiple imputation. Journal of Marriage and Family 77, 277-294.

Zaninotto P, Falaschetti E and Sacker A (2009) Age trajectories of quality of life among older adults: results from the English Longitudinal Study of Ageing. Quality of Life Research 18, 1301-1309.

Cite this article: van den Broek T, Grundy E (2020). Does long-term care coverage shape the impact of informal care-giving on quality of life? A difference-in-difference approach. Ageing \& Society 40, 1291-1308. https://doi.org/10.1017/S0144686X18001708 